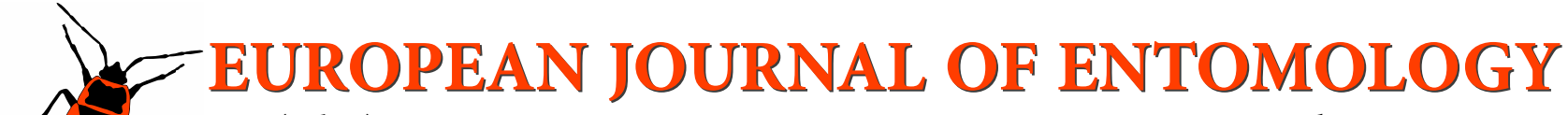 \\ ISSN (online): 1802-8829 \\ http://www.eje.cz \\ Eur. J. Entomol. 116: 492-503, 2019 \\ doi: 10.14411/eje.2019.051 \\ ORIGINAL ARTICLE
}

\section{Local adaptation at fine spatial scale through chromosomal inversions and mito-nuclear epistasis: Findings in Drosophila subobscura (Diptera: Drosophilidae)}

\author{
MARIJA SAVIĆ VESELINOVIĆ ${ }^{1}$, ZoRANA KURBALIJA NOVIČIĆ ${ }^{3,4}$, BoJAN KENIG ${ }^{5}$, MiHAILO JELIĆ ${ }^{1}$, \\ Aleksandra PATENKOVIĆ ${ }^{2}$, MARIJA TANASKOVIĆ ${ }^{2}$, CINo PERTOLDI ${ }^{6,7}$, MarINa STAMENKOVIĆ-RADAK ${ }^{1,2}$ \\ and MARKO ANDJELKOVIĆ ${ }^{8}$ \\ ${ }^{1}$ Faculty of Biology, University of Belgrade, Studentski trg 16, 11000 Belgrade, Serbia; e-mails: marijas@bio.bg.ac.rs, \\ mihailoj@bio.bg.ac.rs, marina@bio.bg.ac.rs \\ ${ }^{2}$ Institute for Biological Research "Siniša Stanković" - National Institute of Republic of Serbia, University of Belgrade, \\ Despot Stefan Blvd. 142, 11000 Belgrade, Serbia; e-mails: aleksandra@ibiss.bg.ac.rs, marija.tanaskovic@ibiss.bg.ac.rs \\ ${ }^{3}$ Animal Ecology, Department of Ecology and Genetics, Evolutionary Biology Center, Uppsala University, Norbyvägen 18D, \\ SE-752 36 Uppsala, Sweden; e-mail: zorana.novicic@neuro.uu.se \\ ${ }^{4}$ Department of Neuroscience, Psychiatry, Uppsala University, SE-751 24 Uppsala, Sweden \\ ${ }^{5}$ Center for the Promotion of Science, Belgrade, Serbia; e-mail: bkenig@cpn.rs \\ ${ }^{6}$ Department 18/Section of Environmental Engineering, Aalborg University, Aalborg, Denmark; e-mail: cp@bio.aau.dk \\ ${ }^{7}$ Aalborg Zoo, Aalborg, Denmark \\ ${ }^{8}$ Serbian Academy of Sciences and Arts, Knez Mihailova 35, 11000 Belgrade, Serbia; e-mail: marko.andjelkovic@sanu.ac.rs
}

Key words. Diptera, Drosophilidae, Drosophila subobscura, genetic differentiation, high dispersion, chromosomal inversion, ND5, microsatellites, local adaptation

\begin{abstract}
To explore local adaptation in wild populations at a fine spatial scale we characterized the genetic variability of eight closely located populations of Drosophila subobscura and its associations with microhabitat environmental conditions. Three different genetic markers were assessed: chromosomal inversions, a SNP of mitochondrial ND5 gene and nuclear microsatellites. Population genetic analyses of chromosomal variability revealed significant genetic differentiation between these populations. Gene arrangement frequencies on the $\mathrm{E}$ chromosome contributed most to these differences. We also investigated role of mitonuclear epistasis in mitochondrial genome differentiation and revealed weak linkage disequilibrium (LD) exclusively between $\mathrm{O}_{3+4}$ inversion arrangement and mitochondrial DNA haplotype $\mathrm{I}$ in two populations. In addition, the trend in the LD between $\mathrm{O}_{\mathrm{ST}}$ chromosomal arrangement and haplotype II was general in the total sample. Microsatellite analysis revealed an absence of stochastic processes, like census reduction, upon population differentiation. Only a small amount of the genetic variation is related to geographic distance, while most $(97 \%)$ is attributable to other factors and in some degree to microhabitat variables (temperature, humidity). The analysis of these factors revealed they effect inversion arrangement frequencies, especially $E_{1+2+9}, E_{S T}$ and $O_{S T}$ Even though this model organism is known for its high mobility and mostly large effective population size, the results presented here reveal that local adaptations can occur even at a small spatial scale. We propose that locally adapted alleles within chromosomal inversions, as well as joint selective pressures acting on mitochondrial and nuclear genomes, are responsible for the observed adaptation to microhabitat conditions.
\end{abstract}

\section{INTRODUCTION}

Local adaptation can be defined as that which results in populations of a species being fittest in their respective local environments (Kawecki \& Ebert, 2004). It is theoretically assumed to result from: population differentiation within a meta-population, divergent natural selection in local habitats and environmental heterogeneity in local habitats in combination with low dispersion and gene flow among populations (Tiffin \& Ross-Ibarra, 2014). Integra- tive population genetic approaches are widely used for investigating various aspects of local adaptation, including genome variability, the variability of environmental factors influencing genetic variability and spatial distributions of populations (Tiffin \& Ross-Ibarra, 2014). The present trend is to combine standard genome-wide analyses and high-resolution searches for candidate genes that are subject to selection and responsible for local adaptations (Savolainen et al., 2013; and references therein). 
However, such searches could be generally restricted to coding regions and dependent on annotation information, largely derived from mutational screening of model species in laboratory environments. Thus, they could potentially miss genes with phenotypic effects that differ between laboratory and natural environments, or have a minor or overestimated phenotypic effects (Pavlidis et al., 2012; Tiffin \& Ross-Ibarra, 2014). Furthermore, many candidate genes and their phenotypic effects have been studied independently, but most ecologically important traits are determined by many interacting loci (Rockman, 2012).

In addition to finding genes involved in local adaptation, a population genetic approach can be used to identify ecological variables that may drive adaptation by habitat selection, manifested in the clustering of individuals of particular genotypes in habitats where they are fittest (Rosenzweig, 1991). From a population genetics perspective, it is important to elucidate relationships between habitat selection and the genetic variability of populations (Levene, 1953; Maynard Smith, 1966; Hoekstra et al., 1985), particularly given the large body of theoretical work indicating how genetic variation can be maintained in heterogeneous environments (Felsenstein, 1976; Hedrick, 1976) by both temporal and spatial variation in selection coefficients.

In most studies on local adaptations it is implicitly or explicitly assumed that a requirement for its evolution is sufficient geographical distance between populations (Nachman et al., 2003) for selective pressures in particular microhabitats to exceed the homogenizing effects of gene flow (Wright, 1969; Felsenstein, 1976; Garcia-Ramos \& Kirkpatrick, 1997; Hendry et al., 2001; Kawecki \& Ebert, 2004). This assumption is supported by various empirical findings (Nosil \& Crespi, 2004). However, Richardson \& Urban (2013) suggest that some studies seriously challenge the presumption that local adaptation occurs only at large geographical scales (Steiner \& Berrang, 1990; Kavanagh et al., 2010; Willi \& Hoffmann, 2012; Richardson et al., 2014). There is, therefore, accumulating evidence that we should revise theoretical presumptions of local adaptation in terms of spatial scale.

Drosophila subobscura is a highly suitable model species for investigating local adaptation using an integrative population genetic approach. Robust and abundant literature is available on this species' population genetics, and many genetic markers have been developed for its population assessment. First of all, it has a rich diversity of inversion polymorphisms, which is associated, to varying degrees, with dynamic abiotic factors both spatially and temporally, and has clear clinal distributions (Krimbas \& Powell, 1992; Živanović et al., 1995; Orengo \& Prevosti, 1996; Andjelković et al., 2003; Balanyà et al., 2004; Stamenkovic-Radak et al., 2008, 2012). Therefore, the inversion polymorphism is important in adaptive processes. Several studies have focused on chromosomal variability of two populations of $D$. subobscura from locations close to each other: two environmentally different types of forest habitats on Mount Goč (Central Serbia). These stud- ies have shown differences in chromosomal arrangement frequencies (Andjelković et al., 2003, 2007; Savković et al., 2004; Stamenkovic-Radak et al., 2008, 2012; Jelić et al., 2009). Stamenkovic-Radak et al. (2008) report the effective population size and chromosomal variation in these nearby populations in repeated samples over several years. They conclude that reduction in population size might have an effect on their genetic differentiation, but they did not address the putative role of local adaptation.

In addition to chromosomal inversion polymorphisms, we also focus here on mtDNA, which in D. subobscura is known to have two prevalent haplotypes (I and II). It has a wide geographic homogeneity with two haplotypes, which exist together with the rare ones derived from the two common ones (Afonso et al., 1990; Castro et al., 1999; Stamenkovic-Radak et al., 2012). Seasonal bottlenecks and population expansion are responsible for the excess of singleton mutations (Castro et al., 2010; Christie et al., 2010). Considering the two most frequent haplotypes, selection possibly acts jointly on combinations of mitochondrial and nuclear alleles, and several studies have analysed the linkage disequilibrium (LD) between mitochondrial haplotypes and chromosomal inversions (Oliver et al., 2002; Jelić et al., 2012a, b). These studies show transient LD due to temporal and spatial differences in the action of ecologically specific selection pressures. Balancing selection such as negative frequency dependent selection may also influence the frequencies of the two main haplotypes (Arnqvist et al., 2016).

The third presumably neutral genetic marker considered here are microsatellites (Pascual et al., 2000, 2001). The Palearctic populations are not genetically differentiated geographically based on microsatellites due to the high gene flow among them. Variability of these markers is relevant to this study because it can show possible effect of neutral processes, such as bottlenecks, on the differentiation between local populations.

Based on the previous results, the objective of the present study was to shed more light on local adaptation at a fine geographical scale in the wild using highly mobile model organism D. subobscura. Accordingly, we genotyped individuals in eight closely positioned microhabitats, using three genetic markers with different adaptive significances: inversion polymorphism, RFLP of mitochondrial ND5 gene and microsatellites. Genotyping was complemented with environmental factors (temperature, humidity) and altitude. We address the question whether in situ environmental factors can lead to genetic differentiation between closely located populations, and re-evaluate the theory on the spatial scale required for local adaptation in natural environments.

\section{MATERIAL AND METHODS}

\section{Population samples and microhabitat characteristics at the localities sampled}

Drosophila subobscura populations were sampled at eight nearby localities $(<15 \mathrm{~km}$ ) (designated $\mathrm{B}, \mathrm{BR}, \mathrm{VB}, \mathrm{PR}, \mathrm{H}, \mathrm{KH}$, $\mathrm{BZ}$ and NB) on Mount Goč, Central Serbia, in early summer. Their latitude, longitude and altitude are presented in Table 1. 
Table 1. Geographical and vegetation descriptions of the localities sampled.

\begin{tabular}{|c|c|c|c|c|c|}
\hline Locality & $\mathrm{N}$ & $E$ & Altitude (m) & Exposition & Phytocenosis \\
\hline$B$ & $43^{\circ} 33^{\prime} 29.1^{\prime \prime}$ & $20^{\circ} 45^{\prime} 17.4^{\prime \prime}$ & 893 & NE & Abieti-fagetumpauperum \\
\hline BR & $43^{\circ} 32^{\prime} 32.5^{\prime \prime}$ & $20^{\circ} 46^{\prime} 32^{\prime \prime}$ & 1111 & SW & Abieti-fagetumtypicum \\
\hline VB & $43^{\circ} 32^{\prime} 33^{\prime \prime}$ & $20^{\circ} 47^{\prime} 10^{\prime \prime}$ & 1256 & NW & Abieti-fagetumpauperum \\
\hline PR & $43^{\circ} 32^{\prime} 54^{\prime \prime}$ & $20^{\circ} 47^{\prime} 11.3^{\prime \prime}$ & 1170 & NW & Abieti-fagetumpauperum \\
\hline $\mathrm{H}$ & $43^{\circ} 33^{\prime} 05.7^{\prime \prime}$ & $20^{\circ} 40^{\prime} 13.7^{\prime \prime}$ & 787 & NW & Ostryo-Quercetumdaleschampii \\
\hline $\mathrm{KH}$ & $43^{\circ} 33^{\prime} 27.4^{\prime \prime}$ & $20^{\circ} 39^{\prime} 07^{\prime \prime}$ & 960 & $E$ & Quercetummontanum \\
\hline$B Z$ & $43^{\circ} 34^{\prime} 04^{\prime \prime}$ & $20^{\circ} 40^{\prime} 09^{\prime \prime}$ & 770 & $E$ & Ostryo-Quercetumdaleschampiiserpentinicum \\
\hline NB & $43^{\circ} 33^{\prime} 32^{\prime \prime}$ & $20^{\circ} 39^{\prime} 59^{\prime \prime}$ & 667 & SE & Fagetummoesiacaemontanum \\
\hline
\end{tabular}

Phytocenological data were provided by the Faculty of Forestry, University of Belgrade, which governs forests on Goč Mountain. These localities represented microhabitats with different vegetation and local microclimatic conditions. Fig. 1 shows the positions of the sites sampled and their relative difference in recorded temperature and humidity.

Nine traps containing fermenting fruit were distributed and mini-data loggers (Testo-174T, Testo AG, Lenzkirch, Germany) were placed centrally at each locality to record temperature and relative humidity simultaneously with population sampling. The accuracy of the data loggers' temperature and relative humidity recordings are $\pm 0.5^{\circ} \mathrm{C}$ (within the range -30 to $+70^{\circ} \mathrm{C}$ ) and $\pm 3 \%$ (within the range 2 to $98 \%$ ), respectively. The mean temperature, relative humidity and their coefficients of variation at each locality were determined for full-day recordings over four days $(24 \mathrm{~h}$ recordings), Table 2.

D. subobscura females were collected at each of the eight localities and individually placed in vials used to establish a total of 388 isofemale (IF) lines: 51, 55, 50, 43, 46, 53, 50 and 40 IF lines derived from females collected at the $\mathrm{B}, \mathrm{BR}, \mathrm{VB}, \mathrm{PR}, \mathrm{H}, \mathrm{KH}, \mathrm{BZ}$ and NB localities, respectively. All IF lines were reared under constant laboratory conditions (temperature $19^{\circ} \mathrm{C}, \mathrm{RH} \sim 60 \%$, light 300 lux and 12L:12D cycle) for one generation and one $F_{1}$ male from each IF line was used for genetic analysis (focusing on the variability of inversion gene arrangement frequencies, distributions of frequencies of the two most frequent mtDNA haplotypes in D. subobscura: I and II, and microsatellite variability).

\section{Genetic variability assessment and data analysis} Inversion polymorphism

One $F_{1}$ male from each IF line was individually crossed with three virgin females from the Küsnacht laboratory strain (homokaryotypic for all five acrocentric chromosomes of the

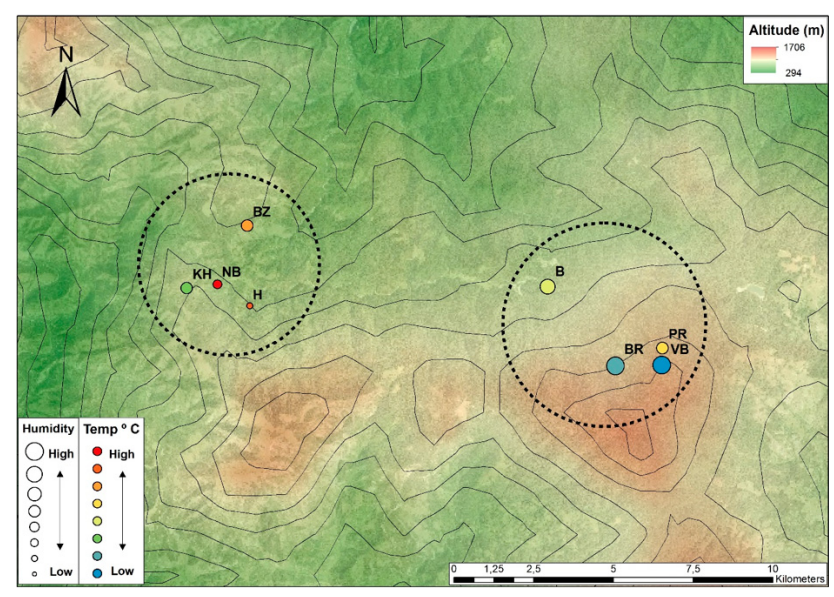

Fig. 1. Map showing the positions of the sites sampled. Mean temperature and relative humidity for each population $(B, B R, V B, P R$, $\mathrm{H}, \mathrm{KH}, \mathrm{BZ}, \mathrm{NB}$ ) are labelled using circle size and colour. species: $\mathrm{A}_{\mathrm{ST}}, \mathrm{J}_{\mathrm{ST}}, \mathrm{U}_{\mathrm{ST}}, \mathrm{E}_{\mathrm{ST}}, \mathrm{O}_{\mathrm{ST}}$ ). Salivary glands from third-instar larvae were squashed and chromosomes were stained with acetoorcein solution. To minimize errors in karyotype determinations, eight larvae from the progeny of each cross were analysed. For the cytological analysis of chromosome arrangements, the chromosome map of Kunze-Mühl \& Müller (1958) and nomenclature according to Kunze-Mühl \& Sperlich (1955) and Krimbas \& Powell (1992) were used.

Differences in individual chromosome arrangement frequencies between pairs of populations were evaluated using the Ztest. Sequential Bonferroni correction (Rice, 1989) was used to adjust significance values to account for false positives arising from multiple simultaneous testing. Furthermore, the genetic differentiation in chromosomal polymorphism between populations was gauged by estimating $F_{S T}$ values, based on differences in chromosome arrangements frequencies, using Arlequin software (v 3.5.1.2) (Excoffier \& Lischer, 2010).

\section{MtDNA variability}

DNA was extracted following Martinez et al. (1992) but without the final alkaline lysis treatment. A 984 bp long region of the mitochondrial ND5 gene was amplified using previously described primers and PCR conditions (Garcia-Martinez et al., 1998). The amplified fragment was digested with FastDigest BsuRI (HaeIII) restriction enzyme (Thermo Fisher Scientific, Waltham, MA, USA) following the manufacturer's recommendations. The digested mtDNA fragments were separated on horizontal $1.5 \%$ gels containing ethidium bromide $(0.1 \mu \mathrm{g} / \mathrm{mL})$. Gene Ruler DNA 100 bp (Thermo Fisher Scientific) was used as a size standard. After electrophoresis, gels were photographed using a Bio-Rad Gel Doc 1000 fluorescence imaging system (Bio-Rad Laboratories, Hercules, CA, USA). The ND5 gene has a polymorphic site that differentiates haplotype I (and rare haplotypes descending from it), from haplotype II (and rare haplotypes descending from it). A HaeIII restriction site is present in haplotype I, but not in haplotype II. Thus, following HaeIII digestion ND5 fragments from haplotype I yield two ( 114 and $\sim 870 \mathrm{bp})$ bands on a gel, while fragments from haplotype II yield just one band. Distribution of haplotypes was determined for each population. Genetic distances in haplotype diversity between pairs of populations were estimated using the $F_{S T}$ statistics, with modification for a haploid data set as heterozygosity data are not available. Arlequin (v 3.5.1.2) software (Excoffier \& Lischer, 2010) was used for these analyses.

\section{Analysis of linkage disequilibrium (LD) between mtDNA and inversion polymorphism}

Linkage disequilibrium among mitochondrial haplotypes and chromosomal arrangements was tested separately in each population, and for the whole sample set according to Jelic et al. (2012a, b) and Oliver et al. (2002). $D$ and $D^{\prime}$ values were estimated (Lewontin, 1964). In order to test the significance of LD, these calculations were followed by Fisher's exact test for independ- 
Table 2. Temperature $(T)$ and relative humidity $(H)$ at the localities sampled.

\begin{tabular}{ccccccccc}
\hline Locality & $\mathrm{B}$ & $\mathrm{BR}$ & $\mathrm{VB}$ & $\mathrm{PR}$ & $\mathrm{H}$ & $\mathrm{KH}$ & $\mathrm{BZ}$ & $\mathrm{NB}$ \\
\hline $\mathrm{T}\left(\min -\max ,{ }^{\circ} \mathrm{C}\right)$ & $8.6-17.9$ & $6.8-16$ & $5.5-15.9$ & $9-19.9$ & $11-28.8$ & $8.9-20.4$ & $11.5-18.9$ & $10.5-28.8$ \\
Mean T \pm SE $\left({ }^{\circ} \mathrm{C}\right)$ & $13.3 \pm 0.2$ & $10.0 \pm 0.1$ & $9.1 \pm 0.1$ & $13.8 \pm 0.2$ & $17.7 \pm 0.3$ & $12.7 \pm 0.2$ & $14.0 \pm 0.2$ & $18.4 \pm 0.4$ \\
$\mathrm{CV}$ & 0.2 & 0.2 & 0.25 & 0.20 & 0.25 & 0.22 & 0.14 & 0.29 \\
$\mathrm{H}(\min -\max , \%)$ & $48.3-99.9$ & $66.2-99.9$ & $69.3-99.9$ & $53.2-87.7$ & $31.9-77.3$ & $42.8-92.3$ & $54.2-96.1$ & $36.2-90$ \\
Mean H \pm SE $(\%)$ & $80.7 \pm 1$ & $85.9 \pm 0.5$ & $86.6 \pm 0.5$ & $74.9 \pm 0.5$ & $55.7 \pm 0.7$ & $72.6 \pm 0.7$ & $73.2 \pm 0.7$ & $64.8 \pm 1.1$ \\
$\mathrm{CV}$ & 0.2 & 0.11 & 0.09 & 0.11 & 0.21 & 0.17 & 0.09 & 0.23 \\
\hline
\end{tabular}

$\mathrm{CV}$ - coefficient of variation.

ence in $2 \times 2$ contingency tables. Only combinations that gave expected numbers $\geq 5$ in all cells were included in the analysis. Independence among tests was enabled by omission of the least frequent arrangement of each of five chromosomes, except for $\mathrm{J}$ chromosome where only two gene arrangements were recorded LD was calculated only for haplotype I. The results for haplotype II have the same value with the opposite sign. Bonferroni correction was applied.

\section{Microsatellite variability}

Eleven polymorphic microsatellite loci were amplified with primers designed by Pascual et al. (2000, 2001). Two microsatellite loci were analysed per chromosomes A, J, U and E (A: dsub05, dsub19; U: dsub03, dsub15; E: dsub13, dsub20; J: dsub18, dsub27). On the O chromosome, the longest one, three microsatellite loci were genotyped (dsub01, dsub02, dsub04) (Santos et al., 2010). Microsatellite loci were amplified using PCR in four multiplex reactions: 1 (dsub27, dsub20, dsub04), 2 (dsub01, dsub18, dsub05), 3 (dsub02, dsub13, dsub19) and 4 (dsub03, dsub15). Four different fluorescent dyes were used to end-label one primer of each primer pair (FAM - dsub01, dsub04, dsub19; NED - dsub02, dsub13, dsub18; PET - dsub05, dsub15, dsub20 and VIC - dsub03, dsub27). The PCR conditions were similar to those of Pascual et al. (2000): $5 \mathrm{~min}$ at $95^{\circ} \mathrm{C}$ followed by 30 cycles of denaturing at $95^{\circ} \mathrm{C}$ for $1 \mathrm{~min}$, annealing at $57^{\circ} \mathrm{C}$ for $30 \mathrm{~s}$ and extension at $72^{\circ} \mathrm{C}$ for $30 \mathrm{~s}$. The exception was that a final elongation of $30 \mathrm{~min}$ at $60^{\circ} \mathrm{C}$ was included and $2 \mu \mathrm{L}(50 \mu \mathrm{g} /$ $\mu \mathrm{L})$ of DNA were added to the total volume $(20 \mu \mathrm{L})$ of the PCR mix. PCR products of amplifications of reactions 1 and 2 were mixed, as the products of the reactions 3 and 4, because coupled products labelled with the same dye did not overlap in the sizes of fragments.

Fragment length was determined using GeneScan LIZ 600 size standard and GeneMapper software on an automated sequencer ABI Prism 3130 (Thermo Fisher Scientific).

Levels of polymorphism for each locus, each population and all loci and populations were estimated using Arlequin v.3.5 software (Excoffier \& Lischer, 2010) by calculating the mean number of alleles - allelic richness $(A)$, mean range in allele size $(R)$, expected heterozygosity $\left(H_{E}\right)$ and observed heterozygosity $\left(H_{O}\right)$. Genetic variability between sampled localities was analysed by the analysis of molecular variance (AMOVA) with the same software. We used the $F_{S T}$ distance method (Weir \& Cockerham, 1984; Excoffier et al., 1992; Weir, 1996).

The possible occurrence of a recent reduction in population size was tested separately for all samples using Bottleneck software (v.1.2.02) (Cornuet \& Luikart, 1996). Wilcoxon signed rank test was used, and two phase mutation model was assumed, since Pascual et al. (2001) demonstrate its accuracy on a similar set of microsatellite loci.

\section{Populations' genetic structure and environmental factors}

To test whether genetic differences between populations could be attributed to distance between populations, the Mantel test (Mantel, 1967) was applied in PAST software (Hammer et al., 2001) using log-transformed distances and $F_{S T}$ values for inversion polymorphism.

Genetic differences based on microsatellite and inversions data were compared using a principal component analysis (PCA) on the allelic frequencies of samples. In order to estimate general pattern within them, as well as within the environmental dataset, correlation loadings between original variables and principal axes (eigenvectors) were obtained.

In order to examine whether patterns of genetic variation correlate with patterns of environmental variation, we performed correlation and regression analyses. The joint effects of environmental variables on chromosomal gene arrangement frequencies was examined with PCs, obtained by principal component analysis on environmental data and individual chromosomal arrangements. The association of individual environmental variables with joint chromosomal gene arrangements was determined using PCs, obtained by PCA of inversion frequencies and individual environmental variables.

In order to identify environmental factors that might be associated with the genetic structure of $D$. subobscura populations we used the hierarchical Bayesian approach of Foll \& Gaggiotti (2006) implemented in GESTE v. 2.0. Specifically, GESTE estimates $F_{S T}$ values for each local population and relates them to environmental factors using a generalized linear model. As this method requires genetic data from codominant markers (e.g. allozymes, microsatellites, or SNPs) and environmental data specific to each local population, we analysed only microsatellites and inversion data. We performed 10 pilot runs of 1000 iterations and default parameters to obtain the parameters of the proposed distributions used by the reversible jump Markov chain Monte

Table 3. The results of AMOVA for chromosomal gene arrangements, RFLP of ND5 gene and microsatellites.

\begin{tabular}{|c|c|c|c|c|c|c|c|}
\hline Genetic marker & d.f. & Source of variation & Sum of squares & Variance components & $\%$ of variation & $F_{S T}$ & $P$-value \\
\hline Inversion polymorphism & $\begin{array}{c}7 \\
740\end{array}$ & $\begin{array}{l}\text { ap } \\
\text { wp }\end{array}$ & $\begin{array}{c}24.94 \\
840.17\end{array}$ & $\begin{array}{l}0.026 \\
1.135\end{array}$ & $\begin{array}{l}2.240 \\
97.76\end{array}$ & 0.022 & $<0.0001^{*}$ \\
\hline RFLP of ND5 & $\begin{array}{c}7 \\
344\end{array}$ & $\begin{array}{l}\text { ap } \\
\text { wp }\end{array}$ & $\begin{array}{c}3.14 \\
84.58\end{array}$ & $\begin{array}{l}0.005 \\
0.246\end{array}$ & $\begin{array}{l}1.840 \\
98.16\end{array}$ & 0.018 & $0.076^{\text {ns }}$ \\
\hline Microsatellite loci & $\begin{array}{c}7 \\
678\end{array}$ & $\begin{array}{l}\text { ap } \\
\text { wp }\end{array}$ & $\begin{array}{c}34.65 \\
2602.43\end{array}$ & $\begin{array}{l}0.013 \\
3.838\end{array}$ & $\begin{array}{c}0.34 \\
99.66\end{array}$ & 0.003 & $0.087^{\mathrm{ns}}$ \\
\hline
\end{tabular}

n.s. - non-significant; ${ }^{*} P$-value $<0.001$; ap - among population; wp - within population. 
Table 4. Gene arrangement frequencies for all chromosomes in all eight populations.

\begin{tabular}{ccccccccc}
\hline Population & $\mathrm{B}$ & $\mathrm{BR}$ & $\mathrm{VB}$ & $\mathrm{PR}$ & $\mathrm{H}$ & $\mathrm{KH}$ & $\mathrm{BZ}$ & $\mathrm{NB}$ \\
\hline $\mathrm{N}$ & 52 & 52 & 49 & 39 & 44 & 51 & 49 & 38 \\
$\mathrm{~A}_{\mathrm{ST}}$ & 0.902 & 0.655 & 0.640 & 0.744 & 0.717 & 0.698 & 0.720 & 0.725 \\
$\mathrm{~A}_{1}$ & 0.039 & 0.255 & 0.220 & 0.163 & 0.239 & 0.245 & 0.240 & 0.175 \\
$\mathrm{~A}_{2}$ & 0.059 & 0.091 & 0.140 & 0.093 & 0.043 & 0.057 & 0.040 & 0.100 \\
$\mathrm{~J}_{\mathrm{ST}}$ & 0.363 & 0.282 & 0.300 & 0.372 & 0.293 & 0.189 & 0.230 & 0.425 \\
$\mathrm{~J}_{1}$ & 0.637 & 0.718 & 0.700 & 0.628 & 0.707 & 0.811 & 0.770 & 0.575 \\
$\mathrm{U}_{\mathrm{ST}}$ & 0.137 & 0.091 & 0.040 & 0.116 & 0.120 & 0.047 & 0.070 & 0.188 \\
$\mathrm{U}_{1}$ & 0.000 & 0.000 & 0.000 & 0.000 & 0.022 & 0.009 & 0.020 & 0.000 \\
$\mathrm{U}_{1+2}$ & 0.735 & 0.655 & 0.790 & 0.663 & 0.663 & 0.679 & 0.720 & 0.700 \\
$\mathrm{U}_{\frac{1+2+6}{2}}$ & 0.127 & 0.255 & 0.170 & 0.221 & 0.196 & 0.264 & 0.190 & 0.113 \\
$\mathrm{E}_{\mathrm{ST}}$ & 0.422 & 0.227 & 0.270 & 0.349 & 0.435 & 0.226 & 0.240 & 0.500 \\
$\mathrm{E}_{8}$ & 0.225 & 0.218 & 0.210 & 0.233 & 0.370 & 0.311 & 0.180 & 0.300 \\
$\mathrm{E}_{1+2+9}$ & 0.324 & 0.509 & 0.500 & 0.384 & 0.163 & 0.425 & 0.570 & 0.163 \\
$\mathrm{E}_{\frac{1+2+9+12}{+2}}$ & 0.029 & 0.045 & 0.020 & 0.035 & 0.033 & 0.038 & 0.010 & 0.038 \\
$\mathrm{O}_{\mathrm{ST}}$ & 0.343 & 0.327 & 0.150 & 0.430 & 0.391 & 0.264 & 0.230 & 0.463 \\
$\mathrm{O}_{6}$ & 0.000 & 0.000 & 0.000 & 0.000 & 0.000 & 0.000 & 0.010 & 0.000 \\
$\mathrm{O}_{\frac{3+4}{}}$ & 0.441 & 0.409 & 0.550 & 0.442 & 0.359 & 0.519 & 0.490 & 0.388 \\
$\mathrm{O}_{\frac{3+4+1}{3}}$ & 0.186 & 0.227 & 0.260 & 0.128 & 0.207 & 0.179 & 0.230 & 0.150 \\
$\mathrm{O}_{\frac{3+4+2}{4}}$ & 0.029 & 0.036 & 0.040 & 0.000 & 0.043 & 0.038 & 0.040 & 0.000 \\
$\mathrm{HZ}$ & 0.598 & 0.623 & 0.550 & 0.622 & 0.592 & 0.623 & 0.600 & 0.581 \\
\hline
\end{tabular}

$\mathrm{N}$ - number of analysed chromosomes; $\mathrm{HZ}$ - degree of heterozygosity.

Carlo method implemented in GESTE. We further applied an additional burn-in of 50,000 iterations and a thinning interval of 20 . All estimates were derived from a sample size of 10,000.

\section{RESULTS}

\section{Inversion polymorphism}

We evaluated the level of genetic variability using inversion polymorphisms of all five acrocentric chromosomes (A, J, U, E, and O). A total of 18 chromosomal arrangements were detected in the whole data set, among them 16 were found in all populations. $U_{1}$ chromosomal arrange- ment was found in three populations only ( $\mathrm{H}, \mathrm{KH}$ and $\mathrm{BZ})$, while arrangement $\mathrm{O}_{6}$ was found only in the $\mathrm{BZ}$ population with a very low frequency (0.01). Gene arrangement frequencies are shown in Table 4. Heterozygosity of all samples was similar.

Z-tests (Table S1) clearly showed significant differences in chromosomal arrangement frequencies between pairs of populations, for all five chromosomes, but most differences were for the $\mathrm{E}$ chromosome, especially in the $\mathrm{E}_{1+2+9}$ arrangement. Large numbers of differences were obtained for the $\mathrm{E}_{\mathrm{ST}}$ and $\mathrm{O}_{\mathrm{ST}}$ arrangements.

The $F_{S T}$ analysis (Table 5) showed that the B, H, NB and $\mathrm{PR}$ populations are significantly differentiated from the other four: BR, KH, VB and BZ.

\section{MtDNA haplotype frequency distributions in the populations sampled}

Haplotype II was more frequent in populations H, PR, $\mathrm{KH}, \mathrm{VB}, \mathrm{BZ}$, while haplotype I was more frequent in $\mathrm{B}$, $\mathrm{NB}$ and $\mathrm{BR}$. The global test of genetic differentiation was not significant $\left(F_{S T}=0.0184 ; P=0.0762\right)$ (Table 3$)$, with the greatest source of variation within putative populations (98.16\%). Most pairwise comparisons were not statistically significant, except between $\mathrm{B}$ and $\mathrm{H}(P<0.05)$, B and $\mathrm{BZ}(P<0.01)$ and NB and $\mathrm{H}(P<0.01)$ localities (Table 5).

\section{Linkage disequilibrium between mtDNA and inversion polymorphism}

The power of the LD analysis of separate populations was low (Table S2). Many arrangements did not fulfil the criteria for testing due to their low frequency within samples. Two populations (H and VB) showed weak LD for the same gene arrangement $\left(\mathrm{O}_{3+4}\right)$ and haplotype I. For population $\mathrm{H}$, the $D^{\prime}$ value was $0.319(P<0.01)$ whereas for $\mathrm{VB}$ it was $0.236(P<0.05)$. Considering the whole sample, weak LD was recorded for the $\mathrm{O}_{\mathrm{ST}}$ arrangement and hap-

Table 5. Population pairwise $F_{S T}$-values based on chromosomal arrangement, haplotype and microsatellite frequencies. After Bonferroni correction only *** labelled values remained significant.

\begin{tabular}{|c|c|c|c|c|c|c|c|c|}
\hline Population & Marker & $B$ & $\mathrm{H}$ & PR & NB & BR & $\mathrm{KH}$ & VB \\
\hline \multirow{3}{*}{$\mathrm{H}$} & M.S. & 0.0015 & & & & & & \\
\hline & ND5 & $0.1256^{*}$ & & & & & & \\
\hline & I.P. & 0.0064 & & & & & & \\
\hline \multirow{3}{*}{ PR } & M.S. & 0.0028 & 0.0076 & & & & & \\
\hline & ND5 & 0.0147 & 0.0141 & & & & & \\
\hline & I.P. & 0.0013 & 0.0115 & & & & & \\
\hline \multirow{3}{*}{ NB } & M.S. & 0.0055 & 0.0051 & 0.0070 & & & & \\
\hline & ND5 & -0.0247 & $0.1060^{* *}$ & 0.0023 & & & & \\
\hline & I.P. & 0.0014 & 0.0065 & 0.0023 & & & & \\
\hline \multirow{3}{*}{$\mathrm{BR}$} & M.S. & 0.0043 & 0.0014 & 0.0061 & 0.0033 & & & \\
\hline & ND5 & -0.0097 & 0.0614 & -0.0151 & -0.0171 & & & \\
\hline & I.P. & $0.0165^{\star * *}$ & $0.0265^{\star * *}$ & 0.0034 & $0.0362^{\star \star *}$ & & & \\
\hline \multirow{3}{*}{$\mathrm{KH}$} & M.S. & 0.0008 & -0.0014 & 0.0043 & 0.0010 & -0.0009 & & \\
\hline & ND5 & 0.0268 & 0.0086 & -0.0249 & 0.0134 & -0.0073 & & \\
\hline & I.P. & $0.0297^{\star * *}$ & $0.0339 * * *$ & $0.0234^{* * *}$ & $0.0616^{\star \star *}$ & 0.0021 & & \\
\hline \multirow{3}{*}{ VB } & M.S. & $0.0076^{* * *}$ & 0.0038 & 0.0034 & 0.0017 & -0.0004 & 0.0006 & \\
\hline & ND5 & 0.0703 & -0.0143 & -0.0128 & 0.0534 & 0.0204 & -0.0141 & \\
\hline & I.P. & $0.0321^{* * *}$ & $0.0564^{* * *}$ & $0.0320 * * *$ & $0.0652^{* * *}$ & $0.0106^{* *}$ & 0.0066 & \\
\hline \multirow[b]{2}{*}{$B Z$} & M.S. & $0.0095^{\star *}$ & $0.0076^{*}$ & 0.0024 & 0.0041 & 0.0040 & 0.0021 & 0.0033 \\
\hline & $\begin{array}{l}\text { ND5 } \\
\text { I.P. }\end{array}$ & $\begin{array}{l}0.0808^{* *} \\
0.0306^{* * *}\end{array}$ & $\begin{array}{c}-0.0176 \\
\mathbf{0 . 0 5 4 4}\end{array}$ & $\begin{array}{c}-0.0085 \\
\mathbf{0 . 0 2 3 3}^{\text {***}}\end{array}$ & 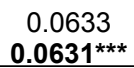 & $\begin{array}{l}0.0278 \\
0.0005\end{array}$ & $\begin{array}{c}-0.0107 \\
0.0040\end{array}$ & $\begin{array}{c}-0.0216 \\
0.0035\end{array}$ \\
\hline
\end{tabular}

${ }^{*} P<0.05,{ }^{* *} P<0.01,{ }^{* *} P<0.001$; Pop - population; M.S. - microsatellites; I.P. - inversion polymorphism. 


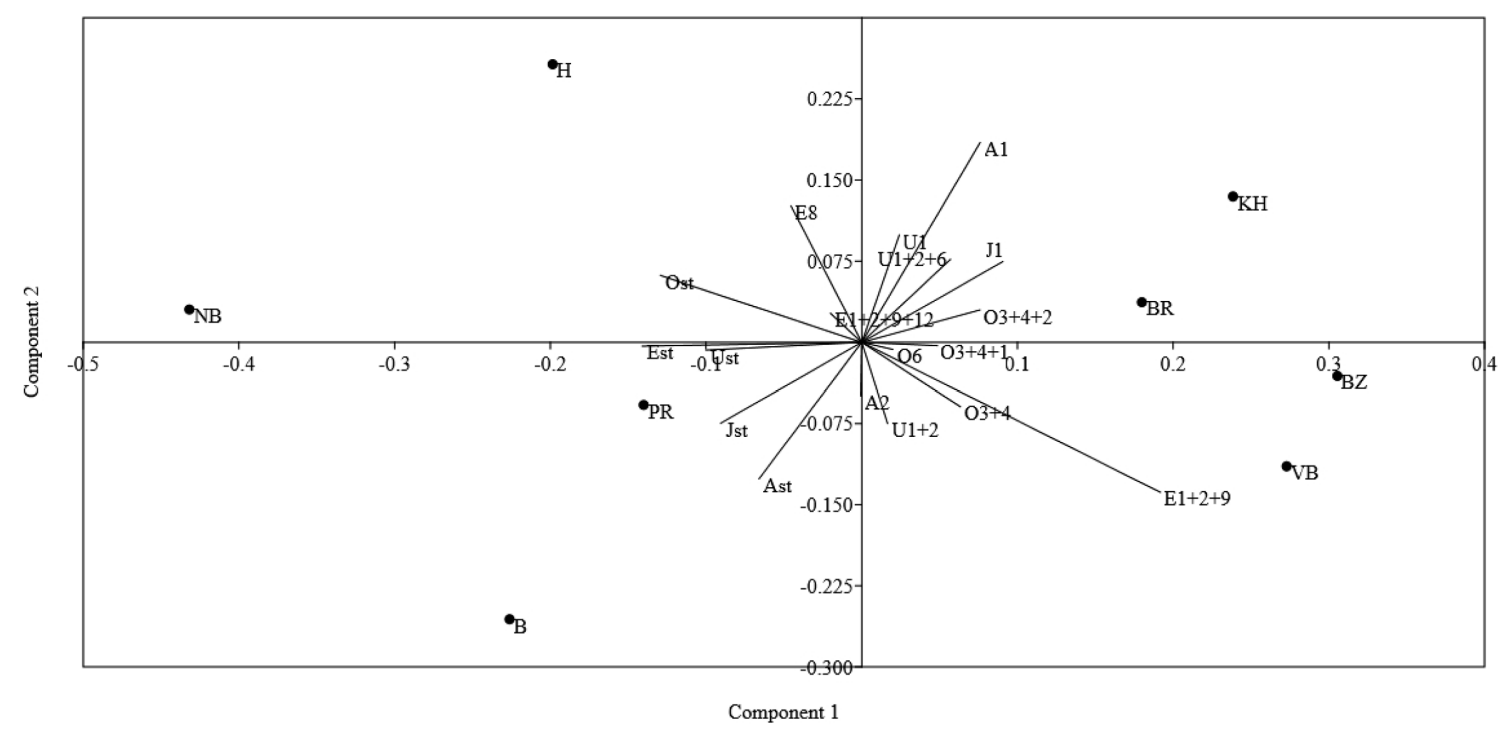

Fig. 2. Biplot of correlation coefficients (loading factors) of chromosome arrangements frequencies with PCA axes 1 and 2.

lotype II (Table S3). This is the consequence of same sign of $D^{\prime}$ value in seven out of eight populations. Other gene arrangements did not show a similar trend across populations. After Bonferroni correction, none of the observed $D^{\prime}$ value was significantly different from zero.

\section{Microsatellite variability}

Standard measures of genetic diversity of microsatellites are presented in the Table S4. The number of alleles varied from 7 (locus dsub13, population $\mathrm{H}$ ) to 25 (locus dsub18, population BR). The mean number of alleles was similar between populations. Expected heterozygosity's were high and very similar in all populations. In all populations, the average observed heterozygosity was lower than the average expected heterozygosity.

The AMOVA showed that the majority of variation is present within populations $(99.66 \%)\left(F_{S T}=0.0034 ; P=0.087\right)$ (Table 3). Most pairwise comparisons were not statistically significant, except between B and VB $(P<0.001)$, B and $\mathrm{BZ}(P<0.01)$ and $\mathrm{H}$ and BZ $(P<0.05)$ localities (Table 5).

The Bottleneck analysis didn't reveal a significant heterozygote excess in populations. In terms of the TPM model there were no significant results regarding recent genetic bottleneck effects on the populations (all $P>0.05$ for Wilcoxon test).

\section{Populations' genetic structure and environmental factors}

The Mantel test revealed that the correlation coefficient (bootstrapped ordinary least squares regression analysis with $95 \%$ confidence intervals) was extremely low $\left(R^{2}=\right.$ $0.0223, P=0.4535)$, implying that around $97 \%$ of the observed genetic variation was not associated with geographic distance.

PCA was done using the frequencies of microsatellite loci, inversion arrangements and environmental data. PC analysis on inversion chromosomal arrangements data revealed that $\mathrm{PC}_{1}$ explains $57.012 \%$ of the variation of inversions in all populations, while $\mathrm{PC}_{2}$ and $\mathrm{PC}_{3}$ explain
$17.448 \%$ and $11.263 \%$, respectively. $\mathrm{PC}_{1}$ had high positive loading for $\mathrm{E}_{\underline{1+2+9}}(0.53)$, moderate for $\mathrm{J}_{1}, \mathrm{~A}_{1}, \mathrm{O}_{\underline{3+4+2}}$ $(0.25 ; 0.21 ; 0.21$ respectively), high negative loadings for standard arrangements of chromosomes $\mathrm{E}$ and $\mathrm{O}(-0.39$; -0.36 respectively) and moderate for $\mathrm{U}$ and $\mathrm{J}(-0.28 ;-0.25$ respectively). So, the loading coefficients of $\mathrm{PC}_{1}$ reveal a weighted contrast between all standard chromosomal gene arrangements (with negative loadings), against the majority complex and simple arrangements (with positive loadings). $\mathrm{PC}_{2}$ had higher positive loadings for $\mathrm{A}_{1}$ and $\mathrm{E}_{8}(0.51$; 0.35 respectively) and high negative loadings for $\mathrm{A}_{\mathrm{ST}}$ and $\mathrm{E}_{\frac{1+2+9}{\mathrm{C}}}(-0.39 ;-0.35$ respectively) (Fig. 2$)$.

$\mathrm{PC}$ analysis of microsatellite data revealed that $\mathrm{PC}_{1}$ explains $18.203 \%$ of the variation of microsatellites in all populations, while $\mathrm{PC}_{2}$ and $\mathrm{PC}_{3}$ explain $16.008 \%$ and $14.884 \%$, respectively. The first three principal components explained only $49.095 \%$ of total variance (unlike variance of inversion arrangement data: $85.723 \%$ ). As the variation recorded by this analysis was minor any further microsatellite analyses were not performed.

The third PCA was performed using environmental variables: the mean temperature, humidity and altitude. The first principal and second components explained $76.485 \%$ and $18.72 \%$ of the total variation, respectively $(95.205 \%$ together). Altitude and temperature are mostly associated with $\mathrm{PC}_{1}$ with positive $(0.63)$ and negative loading $(-0.58)$ respectively, but humidity (with positive loading 0.82) was mostly associated with $\mathrm{PC}_{2}$.

In order to determine the environmental factors that might be associated with the genetic structure of $D$. subobscura populations, we analysed using linear regression the associations of environmental variables with inversion frequencies. When individual chromosome arrangements were considered, the frequencies of $\mathrm{E}_{\mathrm{ST}}, \mathrm{E}_{1+2+9}$ and $\mathrm{E}_{\underline{1+2+9+12}}$ were significantly correlated with only the second principal component of environmental variables. The frequency of $\mathrm{E}_{1+2+9}(r=-0.81, P=0.015)$ was negatively correlated, unlike the $\mathrm{E}_{1+2+9+12}(r=0.78, P=0.021)$ and $\mathrm{E}_{\mathrm{ST}}(r=0.73$, $P=0.041)$ chromosome arrangements. 
When environmental variables were considered, only temperature was significantly correlated with inversion first principal component $\left(R^{2}=0.56, P=0.041\right)$. Altitude and humidity were not correlated with inversion PCs.

Regression approaches employed in GESTE revealed that runs with just a single environmental factor did not produce higher probability models when the factor was included in the model compared to when it was excluded. The model that included mean temperature and the constant had the second highest posterior probability (0.166), while the models containing mean humidity and the constant had a much lower posterior probability (0.091), as also did that with altitude and the constant $(0.084)$. The importance of temperature was supported when looking at the data fit with just the factors alone, because temperature had a posterior probability of 0.291 (humidity and altitude had 0.189 and 0.170 , respectively). We could not analyse the interaction of factors because they were significantly correlated.

\section{DISCUSSION}

The present results on population differentiation obtained using three genetic markers differ markedly. They provide evidence that local adaptations are associated with chromosomal inversions and mito-nuclear epistasis at a very fine spatial scale even in populations of $D$. subobscu$r a$ with high dispersal ability (Begon et al., 1980; Ayala et al., 1989) and high effective population size (Pascual et al., 2001; Kurbalija Novicic et al., 2011, 2013; StamenkovicRadak et al., 2012).

The adaptively neutral nuclear microsatellites were highly variable in all populations. Low share of among population variation, obtained by AMOVA and low values of the $F_{S T}$ indices of pairwise comparisons indicate an absence of neutral genetic differentiation. More importantly, none of the populations have experienced recent bottleneck, which could result in nonadaptive differences between populations.

On the other hand, both AMOVA and pairwise comparisons revealed a higher differentiation based on mitochondrial ND5 gene than that based on microsatellites. Frequencies of haplotypes were in accordance with previously published data (Christie et al., 2010; Jelic et al., 2012a, b). Abundant literature on D. subobscura indicate that both adaptively neutral and selective processes have shaped its mtDNA variability (Castro et al., 2003, 2010; Christie et al., 2004, 2010, 2011; Arnquist et al., 2016). Generally, the previously reported repeatable seasonal dynamics of frequencies (Christie et al., 2010) indicate that mtDNA has been subjected to natural selection. The observed mitochondrial differentiation can be at least partly attributable to stochastic processes, since selection acting on the mt genome is not efficient compared to that on nuclear genes. In this species there are population decays induced by unfavourable conditions during cold winters and dry summers, which are followed by expansions (Castro et al., 2010; Christie et al., 2010) that leave traces in mtDNA variability, in excess of singletons.
Some of the differences in mtDNA frequencies across populations may be at least partly adaptive, especially in light of natural selection acting on joint allelic combinations of the nuclear and mitochondrial genomes. Fitness differences recorded in a laboratory of bearers of different haplotypes of D. subobscura indicate a scenario of epistatic interaction between nuclear and mitochondrial genomes (Christie et al., 2011). Chromosomal inversions are a particularly interesting marker for assessing epistatic interactions in natural populations since the coadaptation hypothesis predicts presence of different alleles in different gene arrangements (Dobzhansky, 1948; Hoffmann et al., 2004). This approach was used to determine the LD between chromosomal and mitochondrial variability in several natural populations of D. subobscura across its range (Oliver et al., 2002; Jelic et al., 2012a, b). Inconsistency in LD results of these studies may indicate temporally or spatially variable epistasis, which is supported by experimentally proven environmentally specific epistasis in insects (Dowling et al., 2007; Arnqvist et al., 2010; Mossman et al., 2016; Rand et al., 2018). Our results are in agreement with this notion since we recorded weak LD between $\mathrm{O}_{3+4}$ gene arrangement and haplotype I, but only in some of the populations. We show that on a small spatial scale, where there is high gene flow, only subtle mito-nuclear LD occurs.

Gregorius \& Ross (1984) propose that negative frequency dependant selection (NFDS) acts to maintain the variation in mtDNA. This was experimentally shown in the seed beetle Callosobruchus maculates (Kazancioglu \& Arnqvist, 2014) and the two main haplotypes of D. subobscura (Oliver et al., 2005; Arnqvist et al., 2016). Contrary to the findings of Arnqvist et al. (2016), García-Martinez et al. (1998) did not record the maintenance of the two haplotypes but favouring and fixation of haplotype II. One possible reason for this discrepancy could be the different environmental conditions in these studies (Arnqvist et al., 2016). So NFDS can act differently depending on the environment. If it acts strongly it will lead to similar frequencies of the two haplotypes, and in its absence there may be greater shifts in the haplotype frequencies.

A great body of evidence supports the adaptive significance of chromosomal variability in D. subobsura. The most illustrative proof comes from the accidental introduction of this species from the Palearctic to South and North Americas. Signs of the correlation coefficients between chromosomal arrangement frequencies and latitude are highly coincident in both native and colonized regions (Prevosti, 1988; Balanya et al., 2003). Among the markers analysed in this study inversion polymorphism revealed the highest genetic differentiation between our closely located populations. Share of between population differentiation is also low for inversions, but nevertheless it is an order of magnitude higher than for neutral microsatellites, and this share is significantly different from zero. Comparisons of differentiation of these two nuclear markers, together with the absence of population bottlenecks indicate that differences between populations in inversion polymorphism are 
adaptive. In addition, most of these adaptive differences were recorded for chromosome E.

Although we detected signs of local adaptation based on chromosomal polymorphism, it is still an open question whether an abiotic and/or biotic factor is mostly responsible for the divergence. It is important to consider the limitations of the approaches used in this study. As we only recorded environmental data over a short interval prior and during sampling the flies we cannot have defined the environmental factors that act throughout the year. The sampling locations were very close, and world climatic data were not applicable in our case. But it is reasonable to assume that the relations of shortly assessed parameters between populations in some respect mirror the long standing ones. In other words, a warm habitat assessed in this way was more likely to be warmer throughout the year due to constant exposure and altitude. Our results indicate it was mostly differences in temperature that were associated with the variation in gene arrangement frequencies between populations. This is particularly the case for the complex arrangement $\mathrm{E}_{1+2+9}$, which is on a chromosome that differs most between populations. The effect of temperature on shaping inversion polymorphism in $D$. subobscura has been previously addressed experimentally, more specifically the thermal preference and heat tolerance of individuals of known genetic backgrounds (Dolgova et al., 2010; Rego et al., 2010). The results indicate that variation in these two traits is not genetically correlated and is associated with different parts of the genome. Dolgova et al. (2010) show that individuals with the warm adapted complex arrangements of $\mathrm{O}$ chromosome have a higher thermal preference. On the other hand, there are no associations between $\mathrm{O}$ chromosomal inversions and heat tolerance. The study of Rego et al. (2010) is not restricted to particular chromosomes. Generally, the carriers of cold-adapted gene arrangements choose low temperatures and are less tolerant to heat stress. However, only variation in chromosome $\mathrm{A}$, and to lower extent in chromosome $\mathrm{O}$, are associated with the thermal preference of $D$. subobscura. On the other hand, only variation in chromosome $\mathrm{E}$ is significantly associated with tolerance of high temperatures. The association between heat tolerance and chromosome E, however, are particularly important. They show that individuals collected in this study not only chose habitats based on their thermal optimum, but more importantly they were adapted to tolerate heat stress, which varies between local populations. Thermal tolerance is of immense importance for survival, since temperature is quite variable in moderate climates (Rego et al., 2010). The importance of temperature, especially $\mathrm{T}_{\text {min }}$ and $\mathrm{T}_{\max }$, was confirmed in this species when inversion polymorphism was analysed in one population in five consecutive years (Galludo et al., 2018).

Our findings indicate that the longstanding view that local adaptation only occurs at large geographical scales due to selection-migration balances should be reviewed. We propose that locally adapted alleles within chromosomal inversions forming coadaptive gene complexes, together with joint selection acting on mitochondrial and nuclear genomes, are responsible for the presence of local adaptations to specific microhabitats in D. subobscura, despite high gene flow. This hypothesis is supported by the significant outbreeding depression reported by Kurbalija et al. (2010) in inter-population hybrids from geographically close but environmentally distinct microhabitats. The occurrence of significant outbreeding depression in the $\mathrm{F}_{1}$ generation could be explained by factors such as underdominance, epistatic interactions or disruption of local adaptations (Edmands, 2007; Escobar et al., 2008) as in the cited study.

This study did not delineate in detail the action of environmental effects on local adaptation. However, this does not compromise our findings of local adaptive differentiation that is apparent from chromosomal variation across populations and possibly the variable presence of LD across populations, both of which are subordinate to the complex synergy of locally present ecological environment. We demonstrate local adaptation on a small spatial scale in a species with high dispersal ability, so the focus of future studies should be shifted from questioning its existence to factors and processes that maintain it.

ACKNOWLEDGEMENTS. This work was supported by grant \#173012 financed by Ministry of Education, Science and Technological Development, Republic of Serbia. This project has received funding from the Serbian Academy of Sciences and Arts under strategic projects programme - grant agreement No 032019. We thank the Faculty of Forestry, University of Belgrade, for providing phytocenological data of sampling localities and the Education Centre of Faculty of Forestry at Mount Goč for providing help and facilities for field research. We thank T. Savić and J. Trajković for help in field sampling, and S. Andersson for designing map of localities. The authors declare no conflict of interest.

\section{REFERENCES}

Afonso J.M., Volz A., Hernandez M., Ruttkay H., Gonzalez M., Larruga J.M., Cabrera V.M. \& Sperlich D. 1990: Mitochondrial DNA variation and genetic structure in Old-World populations of Drosophila subobscura. - Mol. Biol. Evol. 7: 123-142.

Andjelković M., Savković V. \& Kalajdžić P. 2003: Inversion polymorphism in Drosophila subobscura from two different habitats from the mountain of Goc. - Hereditas 138: 241-243.

Andjelković M., Stamenković-Radak M., Kurbalija Z., Kenig B., Rašić G., Savković V., Kalajdžić P., Savić T. \& Savić M. 2007: The study of chromosomal inversion polymorphism of Drosophila subobscura over years in two different habitats from the mountain Goč. — Genetika 39: 155-167.

Arnqvist G., Dowling D.K., Eady P., Gay L., Tregenza T., Tuda M. \& Hosken D.J. 2010: Genetic architecture of metabolic rate: environment specific epistasis between mitochondrial and nuclear genes in an insect. — Evolution 64: 3354-3363.

Arnqvist G., Kurbalija Novičić Z., Castro J.A. \& Sayadi A. 2016: Negative frequency dependent selection on sympatric mtDNA haplotypes in Drosophila subobscura. - Hereditas 153: $15-20$.

Ayala F.J., Serra L. \& Prevosti A. 1989: A grand experiment in evolution: Drosophila subobscura colonization of the Americas. - Genome 31: 246-255.

Balanya J., Serra L., Gilchrist G.W., Huey R.B., Pascual M., Mestres F. \& Solé E. 2003: Evolutionary pace of chromo- 
somal polymorphism in colonizing populations of Drosophila subobscura: an evolutionary time series. - Evolution 57: 1837-1845.

Balanyà J., Solé E., Oller J., Sperlich D. \& Serra L. 2004: Long-term changes in the chromosomal inversion polymorphism of Drosophila subobscura. II. European populations. J. Zool. Syst. Evol. Res. 42: 191-201.

Begon M., Krimbas C.B. \& Loukas M. 1980: The genetics of Drosophila subobscura. XV. Effective size of a natural population estimated by three independent methods. - Heredity 45 : 335-350.

Castro J.A., Ramon M., Picornell A. \& Moya A. 1999: The genetic structure of Drosophila subobscura populations form the islands of Majorca and Minorca (Balearic Islands, Spain) based on allozymes and mitochondrial DNA. - Heredity 83: $71-279$.

Castro J.A., Oliver P., Christie J.S., Picornell A., Ramon M.M. \& Moya A. 2003: Assortative mating and fertility in two Drosophila subobscura strains with different mitochondrial DNA haplotypes. - Genetica 119: 295-301.

Castro J.A., Barrio E., González A., Picornell A., Ramon M.M. \& Moya A. 2010: Nucleotide diversity of a ND5 fragment confirms that population expansion is the most suitable explanation for the mtDNA haplotype polymorphism of Drosophila subobscura. — Genetica 138: 819-829.

Christie J.S., Castro J.A., Oliver P., Picornell A., Ramon M.M. \& Moya A. 2004: Fitness and life-history traits of the two major mitochondrial DNA haplotypes of Drosophila subobscura. Heredity 93: 371-378.

Christie J.S., Picornell A., Moya A., Ramon M.M. \& Castro J.A. 2010: Dynamics of the mtDNA haplotype variability in a Drosophila subobscura population over a two year period. Open Evol. J. 4: 23-30.

Christie J.S., Picornell A., Moya A., Ramon M.M. \& Castro J.A. 2011: Mitochondrial DNA effects on fitness in Drosophila subobscura. - Heredity 107: 239-245.

CoRnuet J.M. \& Luikart G. 1996: Description and power analysis of two tests for detecting recent population bottlenecks from allele frequency data. - Genetics 144: 2001-2014.

DoBZHANSKY T. 1948: Chromosomal variation in populations of Drosophila pseudoobscura which inhabit northern Mexico. Am. Nat. 82: 97-106.

Dolgova O., Rego C., Calabria G., Balanyà J., Pascual M., Rezende E.L. \& SANTos M. 2010: Genetic constraints for thermal coadaptation in Drosophila subobscura. - BMC Evol. Biol. 10: 363, 16 pp.

Dowling D.K., AbIEgA K.C. \& Arnqvist G. 2007: Temperaturespecific outcomes of cytoplasmic-nuclear interactions on eggto-adult development time in seed beetles. - Evolution 61: 194-201.

EDMANDS S. 2007: Between a rock and a hard place: evaluating the relative risks of inbreeding and outbreeding for conservation and management. - Mol. Ecol. 16: 463-475.

Escobar J.S., Nicot A. \& David P. 2008: The different sources of variation in inbreeding depression, heterosis, and outbreeding depression in a metapopulation of Phisa acuta. - Genetics 180: $1593-1608$.

EXCOFFIER L. \& Lischer H.E.L. 2010: Arlequin suite ver 3.5: A new series of programs to perform population genetics analyses under Linux and Windows. - Mol. Ecol. Resour. 10: 564-567.

Excoffier L., Smouse P. \& Quattro J. 1992: Analysis of molecular variance inferred from metric distances among DNA haplotypes: Application to human mitochondrial DNA restriction data. - Genetics 131: 479-491.
FeLSENSTEIN J. 1976: The theoretical population genetics of variable selection and migration. - Annu. Rev. Genet. 10: 253-280.

Foll M. \& GAGGIOTTI O. 2006: Identifying the environmental factors that determine the genetic structure of populations. $-\mathrm{Ge}$ netics 174: 875-891.

Galludo M., Canals J., Pineda-Cirera L., Esteve C., Rossello M., Balanya J., Arenas C. \& Mestres F. 2018: Climatic adaptation of chromosomal inversions in Drosophila subobscura. - Genetica 146: 433-441.

Garcia-Ramos G. \& KirKPatrick M. 1997: Genetic models of adaptation and gene flow in peripheral populations. - Evolution 51: $21-28$.

Garcia-Martinez J., Castro J.A., Ramon M., Latorre A. \& MoyA A. 1998: Mitochondrial DNA haplotype frequency in natural and experimental populations of Drosophila subobscura. - Genetics 149: 1377-1382.

Gregorius H.R. \& Ross M.D. 1984: Selection with gene-cytoplasm interactions. I. Maintenance of cytoplasm polymorphisms. - Genetics 107: 165-178.

Hammer Ø., Harper D.A.T. \& Ryan P.D. 2001: PAST: Paleontological statistics software package for education and data analysis. - Palaeontol. Electron. 4(1): 4, 9 pp.

HEDRICK P.W. 1976: Genetic variation in a heterogeneous environment. II. Temporal heterogeneity and directional selection. - Genetics 84: 145-150.

Hendry A.P., Day T. \& TAYlor E.B. 2001: Population mixing and the adaptive divergence of quantitative traits in discrete populations: a theoretical framework for empirical tests. - Evolution 55: 459-466

Hoekstra R.F., Bijlsma R. \& Dolman A.J. 1985: Polymorphism from environmental heterogeneity: models are only robust if the heterozygote is close in fitness to the favoured homozygote in each environment. - Genet. Res. 45: 299-314.

Hoffmann A., Sgro C.M. \& Weeks A. 2004: Chromosomal inversion polymorphism and adaptation. - Trends. Ecol. Evol. 19: 482-488.

Jelić M., Kenig B., Kurbalija Z., Stamenkovic-Radak M. \& ANDJELKOVIC M. 2009: Intra-species differentiation among Drosophila subobscura from different habitats in Serbia. Arch. Biol. Sci. 61: 513-521.

Jelić M., Castro J.A., Kurbalija Novičíc Z., Kenig B., DimitriJević D., Savić Veselinović M., Jovanović M., Milovanović D., StamenKović-RadaK M. \& AnDJELKović M. 2012a: Absence of linkage disequilibria between chromosomal arrangements and mtDNA haplotypes in natural populations of Drosophila subobscura from the Balkan Peninsula. - Genome 55: 214-221.

Jelić M., Kenig B., Tanasković M., Stamenković-Radak M. \& ANDJELKović M. 2012b: Relationship between chromosomal and mitochondrial DNA variability of Drosophila subobscura population from the Lazar's River Canyon. - Genetika 44: 409-417.

Kavanagh K.D., Haugen T.O., Gregersen F., Jernvall J. \& VøllESTAD L.A. 2010: Contemporary temperature-driven divergence in a Nordic freshwater fish under conditions commonly thought to hinder adaptation. - BMC Evol. Biol. 10: 350, 13 pp.

KAWECKI T.J. \& EBERT D. 2004: Conceptual issues in local adaptation. - Ecol. Lett. 7: 1225-1241.

KAZANCIOĞLU E. \& ARNQvist G. 2014: The maintenance of mitochondrial genetic variation by negative frequency-dependent selection. - Ecol. Lett. 17: 22-27.

Krimbas C.B. \& Powell J.R. 1992: Drosophila Inversion Polymorphism. CRC, Boca Raton, FL, 576 pp.

KunZe-Mühl E. \& MÜlleR E. 1958: Weitere Untersuchungen über die chromosomale, Struktur und die natürlichen Struk- 
turtypen von Drosophila subobscura Coll. - Chromosoma (Berl.) 9: 559-570.

Kunze-MüHL E. \& Sperlich D. 1955: Inversionen und chromosomale Strukturtypen bei Drosophila subobscura Coll. $-Z$. Indukt. Abstam. Vererbungs. 87: 65-84.

Kurbalija Z., Stamenković-Radak M., Pertoldi C. \& AndjelkoVIĆ M. 2010: Outbreeding causes developmental instability in Drosophila subobscura. — Evol. Ecol. 24: 839-864.

Kurbalija Novičić Z., Jelić M., Jovanović M., Dimitrijević D. Savić Veselinović M. Stamenković-RadaK M. \& Andjelković M. 2011: Microsatellite variability of Drosophila subobscura populations from the central Balkans. - Evol. Ecol. Res. 13 479-494.

Kurbalija Novičić Z., Jelić M., Savić T., Savić Veselinović M., Dimitrijević D., Jovanović M., Kenig B., Stamenković-RadaK M. \& Andjelković M. 2013: Effective population size in Drosophila subobscura: ecological and molecular approaches. —J. Biol. Res.-Thess. 19: 65-74.

LeVene H. 1953: Genetic equilibrium when more than one ecological niche is available. - Am. Nat. 87: 331-333.

LEWONTIN R.C. 1964: The interaction of selection and linkage. I. General considerations; heterotic models. - Genetics 49 : 49-67.

Mantel N. 1967: The detection of disease clustering and a generalized regression approach. - Cancer Res. 27: 209-220.

Martinez D., Moya A., Latorre A. \& Fereres A. 1992: Mitochondrial DNA variation in Rhopalosiphum padi (Homoptera: Aphididae) populations from four Spanish localities. - Ann. Entomol. Soc. Am. 85: 241-246.

Maynard Smith J. 1966: Sympatric speciation. - Am. Nat. 100: 637-650.

Mossman J., Biancani L., Zhu C.-T. \& Rand D. 2016: Mitonuclear epistasis for development time and its modification by diet in Drosophila. - Genetics 203: 463-484.

Nachman W.M., Hoekstra H.E. \& D'Agostino S.L. 2003: The genetic basis of adaptive melanism in pocket mice. - Proc. Natl. Acad. Sci. USA 100: 5268-5273.

NosiL P. \& CRESPI B.J. 2004: Does gene flow constrain trait divergence or vice-versa? A test using ecomorphology and sexual isolation in Timema cristinae walking-sticks. - Evolution 58: 101-112.

Oliver P., Castro J.A., Picornell A., Ramon M.M., Sole E., Balanya J., Serra L., Lattore A. \& Moya A. 2002: Linkage disequilibria between mtDNA haplotypes and chromosomal arrangements in a natural population of Drosophila subobscura. - Heredity 89: 133-138.

Oliver P., Balanya J., Ramon M.M., Picornell A., Serra L., Moya A. \& CAStro J.A. 2005: Population dynamics of the 2 major mitochondrial DNA haplotypes in experimental populations of Drosophila subobscura. - Genome 48: 1010-1018.

Orengo D.J. \& Prevosti A. 1996: Temporal changes in chromosomal polymorphism of Drosophila subobscura related to climatic change. - Evolution 50: 1346-1350.

Pascual M., Schug M.D. \& Aquadro C.F. 2000: High density of long dinucleotide microsatellites in Drosophila subobscura. Mol. Biol. Evol. 17: 1259-1267.

Pascual M., Aquadro C.F., Soto V. \& Serra L. 2001: Microsatellite variation in colonizing and Palearctic populations of Drosophila subobscura. - Mol. Biol. Evol. 18: 731-741.

Pavlidis P., Jensen J.D., Stephan W. \& Stamatakis A. 2012: A critical assessment of storytelling: gene ontology categories and the importance of validating genomic scans. - Mol. Biol. Evol. 29: 3237-3248.

Prevosti A., Ribo G., Serra L., Aguade M., Balaña J., Monclus M. \& Mestres F. 1988: Colonization of America by Drosophi- la subobscura: Experiment in natural populations that supports the adaptive role of chromosomal-inversion polymorphism. Proc. Natl. Acad. Sci. USA 85: 5597-5600.

Rand D., Mossman J. \& ZhU L. 2018: Mitonuclear epistasis, genotype-by-environment interactions, and personalized genomics of complex traits in Drosophila. - IUBMB Life 70: 1275-1288.

Rego C., Balanya J., Fragata I., Matos M., Rezende E.L. \& SAntos M. 2010: Clinal patterns of chromosomal inversion polymorphisms in Drosophila subobscura are partly associated with thermal preferences and heat stress resistance. - Evolution 64: 385-397.

Rice W.R. 1989: Analyzing tables of statistical tests. — Evolution 43: 223-225.

RichARDSON J.L. \& URBAN M.C. 2013: Strong selection barriers explain microgeographic adaptation in wild salamander populations. - Evolution 67: 1729-1740.

Richardson J.L., Urban M., Bolnick D.I. \& Skelly D.K. 2014: Microgeographic adaptation and the spatial scale of evolution. — Trends. Ecol. Evol. 29: 165-176.

RocKMAN M.V. 2012: The QTN program and the alleles that matter for evolution: all that's gold does not glitter. - Evolution 66: 1-17.

RosenZweIG M.L. 1991: Habitat selection and population interactions: the search for mechanism. - Am. Nat. 137: S5-S28.

Santos J., Serra L., Solé E. \& Pascual M. 2010: FISH mapping of microsatellite loci from Drosophila subobscura and its comparison to related species. - Chromos. Res. 18: 213-226.

Savković V., Stamenković-Radak M. \& Andjelković M. 2004: Diurnal variability of gene arrangement frequencies in Drosophila subobscura populations from two habitats. - J. Zool. Syst. Evol. Res. 42: 208-214.

Savolainen O., Lascoux M. \& Merilä J. 2013: Ecological genomics of local adaptation. - Nat. Rev. Gen. 14: 807-820.

Sperlich D. \& Feuerbach H. 1966: Ist der chromosomale Struktur-polymorphismus von Drosophila subobscura stabil oder flexibel? - Z. Indukt. Abstam. Vererbungs. 98: 16-24.

StamenKović-Radak M., Rasić G., SAvić T., KalajdžIĆ P., KuRBalija Z., Kenig B. \& AnĐelković M. 2008: Monitoring of the genetic structure of natural populations: change of the effective population size and inversion polymorphism in Drosophila subobscura. - Genetica 133: 57-63.

Stamenković-Radak M., Jelić M., Kurbalija Novičcí Z., Kenig B., TAnasković M. \& Andjelković M. 2012: Balkan glacial history and modern Drosophila subobscura population genetics. - Evol. Ecol. Res. 14: 839-858.

Steiner K.C. \& BerRang P.C. 1990: Microgeographic adaptation to temperature in pitch pine progenies. - Am. Midl. Nat. 123: 292-300.

Tiffin P.M. \& Ross-IBarRa J. 2014: Advances and limits of using population genetics to understand local adaptation. - Trends. Ecol. Evol. 29: 673-680.

WeIR B.S. 1996: Genetic Data Analysis II: Methods for Discrete Population Genetic Data. Sinauer Associates, Sunderland, MA, 445. pp.

Weir B.S. \& Cockerham C.C. 1984: Estimating F-statistics for the analysis of population structure. - Evolution 38: 13581370 .

Willi Y. \& HoffmanN A.A. 2012: Microgeographic adaptation linked to forest fragmentation and habitat quality in the tropical fruit fly Drosophila birchii. — Oikos 121: 1627-1637.

Wright S. 1969: Evolution and the Genetics of Populations, Vol. 2: The Theory of Gene Frequencies. University of Chicago Press, Chicago, 520 pp. 
Živanović G., Milanović M. \& Andjelković M. 1995: Chromosomal inversion polymorphism of Drosophila subobscura from Jastrebac Mountain shows temporal and habitat-related changes. - J. Zool. Syst. Evol. Res. 33: 81-83.

Received October 4, 2019; revised and accepted December 3, 2019

Published online December 30, 2019

Table S1. Differences in inversion arrangement frequencies obtained using $Z$ statistics.

\begin{tabular}{|c|c|c|c|c|c|c|c|c|c|c|c|c|c|c|c|c|c|c|}
\hline & $\mathrm{A}_{\mathrm{ST}}$ & $A_{1}$ & $\mathrm{~A}_{2}$ & $\mathrm{~J}_{\mathrm{ST}}$ & $J_{1}$ & $U_{S T}$ & $U_{1}$ & $U_{1+2}$ & $U_{1+2+6}$ & $E_{S T}$ & $\mathrm{E}_{8}$ & $E_{1+2+9}$ & $\mathrm{E}_{1+2+9+12}$ & $\mathrm{O}_{\mathrm{ST}}$ & $\mathrm{O}_{6}$ & $\mathrm{O}_{3+4}$ & $\mathrm{O}_{\underline{3+4+1}}$ & $\mathrm{O}_{\underline{3+4+2}}$ \\
\hline $\mathrm{NB} / \mathrm{H}$ & & & & * & * & & & & * & & & & & & & & & \\
\hline NB/B & ** & $* *$ & & & & & & & & & & *** & & * & & & & * \\
\hline NB/VB & & & & * & * & $* * *$ & & * & & $* * *$ & * & *** & & $* * *$ & & ** & * & * \\
\hline NB/BZ & & & & $* * *$ & $\star \star \star *$ & $* * *$ & & & * & $* * *$ & $* *$ & $* * *$ & & $* * *$ & & & & * \\
\hline NB/BR & & & & ** & ** & ** & & & *** & $* * *$ & & *** & & ** & & & & * \\
\hline $\mathrm{NB} / \mathrm{KH}$ & & & & $* \star *$ & $\star \star \star \star ~$ & 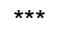 & & & $* * *$ & $* * *$ & & $* * *$ & & $* * *$ & & * & & * \\
\hline NB/PR & & & & & & & & & ** & $* *$ & & *** & & & & & & \\
\hline $\mathrm{H} / \mathrm{B}$ & $* * *$ & $* * *$ & & & & & * & & & & $* *$ & *** & & & & & & \\
\hline $\mathrm{H} / \mathrm{VB}$ & & & * & & & ** & * & ** & & $* * *$ & *** & *** & & $* * *$ & & $* * *$ & & \\
\hline $\mathrm{H} / \mathrm{BZ}$ & & & & & & & & & & $* * *$ & $* * *$ & $* * *$ & & $* * *$ & & & & ** \\
\hline $\mathrm{H} / \mathrm{BR}$ & & & & & & & ** & & & $* \star *$ & $\star \star * *$ & *** & & & & & & \\
\hline $\mathrm{H} / \mathrm{KH}$ & & & & * & * & $\star \star *$ & & & & $* \star *$ & & $* * *$ & & $* *$ & & ** & & \\
\hline $\mathrm{B} / \mathrm{VB}$ & $* * *$ & $* * *$ & & & & $* * *$ & & & & ** & & *** & & $* * *$ & & * & & \\
\hline $\mathrm{B} / \mathrm{BZ}$ & $* * *$ & $\star * *$ & & ** & ** & * & * & & & $\star * *$ & & *** & & * & & & & \\
\hline B/BR & $* * *$ & $* * *$ & & & & & & & $* \star *$ & $* * *$ & & $\star * *$ & & & & & & \\
\hline $\mathrm{B} / \mathrm{KH}$ & $* * *$ & $* * *$ & & $* * *$ & $\star \star \star *$ & $* *$ & & & $* * *$ & $* * *$ & & * & & & & & & \\
\hline VB/BZ & & & * & & & & * & & & & & & & * & & & & \\
\hline VB/BR & & & & & & * & & ** & & & & & & $* * *$ & & ** & & \\
\hline VB/KH & & & & $* *$ & $* *$ & & & * & * & & * & & & $* *$ & & * & & \\
\hline BZ/BR & & & & & & & * & & & & & & * & * & & & & \\
\hline $\mathrm{BZ} / \mathrm{KH}$ & & & & & & & & & & & $* *$ & ** & & & & & & \\
\hline $\mathrm{BR} / \mathrm{KH}$ & & & & * & * & & & & & & & & & & & * & & \\
\hline $\mathrm{PR} / \mathrm{H}$ & & & & & & & & & & & ** & *** & & & & & * & ** \\
\hline $\mathrm{PR} / \mathrm{B}$ & ** & ** & & & & & & & * & & & & & & & & & * \\
\hline PR/VB & & & & & & ** & & ** & & & & * & & $* * *$ & & * & ** & $* *$ \\
\hline PR/BZ & & & & ** & $\star * *$ & & & & & * & & *** & & *** & & & * & ** \\
\hline PR/BR & & & & & & & & & & ** & & * & & * & & & * & * \\
\hline $\mathrm{PR} / \mathrm{KH}$ & & & & $* * *$ & 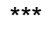 & * & & & & ** & & & & $* * *$ & & & & ** \\
\hline
\end{tabular}

${ }^{*} P<0.05,{ }^{* *} P<0.01,{ }^{* * *} P<0.001$. 
Table S2. LD analysis for each population.

\begin{tabular}{|c|c|c|c|c|c|c|c|c|c|c|c|c|c|c|c|}
\hline \multicolumn{4}{|c|}{$\mathrm{H}$} & \multicolumn{4}{|c|}{$B$} & \multicolumn{4}{|c|}{ PR } & \multicolumn{4}{|c|}{ NB } \\
\hline & $D$ & $D^{\prime}$ & $P$ & & $D$ & $D^{\prime}$ & $P$ & & $D$ & $D^{\prime}$ & $P$ & & $D$ & $D^{\prime}$ & $P$ \\
\hline$A_{s t}$ & 0.0058 & 0.0513 & - & $A_{\text {st }}$ & 0.0232 & 0.328 & - & $A_{\text {st }}$ & 0.0048 & 0.044 & - & $A_{\text {st }}$ & \multicolumn{2}{|c|}{$-0.0082-0.0667$} & - \\
\hline$A_{1}$ & -0.0139 & -0.1461 & - & $A_{1}$ & -0.0045 & -0.16 & - & $A_{1}$ & \multicolumn{2}{|c|}{$-0.0273-0.4423$} & - & $A_{1}$ & \multirow{2}{*}{\multicolumn{2}{|c|}{$\begin{array}{rr}0.0163 & 0.222 \\
-0.0082 & -0.125\end{array}$}} & - \\
\hline $\mathrm{A}_{2}$ & 0.008 & 0.2292 & - & $\mathrm{A}_{2}$ & -0.0187 & -0.44 & - & $\underline{A}_{2}$ & \multicolumn{2}{|c|}{$0.0226 \quad 0.3958$} & - & $\mathrm{A}_{2}$ & & & - \\
\hline $\mathrm{J}_{\mathrm{st}}^{2}$ & -0.0234 & -0.2238 & 0.4312 & $\mathrm{~J}_{\mathrm{st}}^{2}$ & 0.0017 & 0.0118 & 1 & $\mathrm{~J}_{\mathrm{st}}^{\underline{t}}$ & \multirow{2}{*}{\multicolumn{2}{|c|}{$\begin{array}{rr}0.0369 & 0.1761 \\
-0.0369 & -0.1761\end{array}$}} & 0.285 & $\mathrm{~J}_{\mathrm{st}}$ & \multicolumn{2}{|c|}{$-0.0163-0.0667$} & 0.631 \\
\hline$J_{1}$ & 0.0234 & 0.2238 & 0.4312 & $J_{1}$ & -0.0017 & -0.0118 & 1 & $J_{1}$ & & & 0.285 & $J_{1}$ & \multirow{2}{*}{\multicolumn{2}{|c|}{$\begin{array}{rr}0.0163 & 0.0667 \\
-0.0204 & -0.1923\end{array}$}} & 0.631 \\
\hline $\mathrm{U}_{\mathrm{st}}$ & 0.0288 & 0.2993 & 0.1884 & $U_{\text {st }}$ & -0.0232 & -0.328 & - & $U_{\text {st }}$ & 0.038 & 1 & - & $U_{s t}$ & & & 0.537 \\
\hline $\mathrm{U}_{1}^{\text {st }}$ & -0.0095 & -1.0000 & - & $U_{1}^{s t}$ & - & - & - & $\mathrm{U}_{1}^{\mathrm{st}}$ & - & - & - & $U_{1}^{s t}$ & \multicolumn{2}{|l|}{-} & - \\
\hline$U_{1+2}^{1}$ & -0.0259 & -0.1287 & 0.2802 & $\mathrm{U}_{1+2}^{1}$ & -0.0227 & -0.2139 & - & $U_{1+2}^{7}$ & -0.0868 & -0.4563 & 0.067 & $U_{1+2}^{1}$ & \multicolumn{2}{|c|}{$0.0061 \quad 0.0375$} & 0.537 \\
\hline$U_{1+2+6}^{\frac{1+2}{1+2}}$ & 0.0066 & 0.0750 & - & $U_{1+2+6}^{\frac{1+2}{2}}$ & 0.0459 & 0.7941 & - & $U_{1+2+6}^{\frac{1+2}{1+2}}$ & 0.0487 & 0.3203 & 0.067 & $U_{\underline{1+2+6}}^{\frac{1+2}{2}}$ & \multicolumn{2}{|c|}{$0.0143 \quad 0.3333$} & - \\
\hline $\mathrm{E}_{\mathrm{st}}$ & -0.0161 & -0.1167 & 0.6181 & $\mathrm{E}_{\mathrm{st}}$ & -0.0099 & -0.042 & 0.821 & $\mathrm{E}_{\mathrm{st}}$ & -0.0244 & -0.1502 & 0.422 & $\mathrm{E}_{\mathrm{st}}$ & \multicolumn{2}{|c|}{$-0.0388-0.1979$} & 0.457 \\
\hline$E_{8}$ & 0.0292 & 0.1338 & 0.3163 & $\mathrm{E}_{8}$ & -0.0204 & -0.16 & 0.421 & $\mathrm{E}_{8}$ & 0.0392 & 0.275 & 0.236 & $\mathrm{E}_{8}$ & \multicolumn{2}{|c|}{$-0.0041-0.0454$} & 1 \\
\hline$E_{1+2+9}$ & -0.0124 & -0.1868 & - & $E_{1+2+9}$ & 0.0278 & 0.2059 & 0.342 & $E_{1+2+9}$ & -0.0071 & -0.044 & 0.789 & $E_{1+2+9}$ & \multicolumn{2}{|c|}{$0.0245 \quad 0.2222$} & 0.283 \\
\hline $\mathrm{E}_{1+2+9+12}$ & -0.0007 & -0.0513 & - & $E_{1+2+9+12}$ & 0.0025 & 0.1765 & - & $E_{1+2+9+12}$ & -0.0077 & -1 & - & $\mathrm{E}_{1+2+9+12}^{\stackrel{1+2+9}{1}}$ & \multicolumn{2}{|c|}{$0.0184 \quad 1$} & - \\
\hline$\frac{1+2+5+12}{\mathrm{O}_{\mathrm{st}}}$ & -0.0383 & -0.2885 & 0.3048 & $\frac{1+2+y+12}{\mathrm{O}_{\mathrm{st}}}$ & -0.0317 & -0.16 & 0.347 & $\frac{1+2+9+12}{\mathrm{O}_{\mathrm{st}}}$ & -0.0053 & -0.0301 & 1 & $\mathrm{O}_{\mathrm{st}}$ & \multicolumn{2}{|c|}{$-0.0531-0.2222$} & 0.074 \\
\hline $\mathrm{O}_{6}$ & - & - & - & $\mathrm{O}_{6}$ & - & - & - & $\mathrm{O}_{6}$ & - & - & - & $\mathrm{O}_{6}$ & \multicolumn{2}{|c|}{$-\quad \quad-$} & - \\
\hline $\mathrm{O}_{\underline{3+4}}$ & 0.0698 & 0.3194 & $0.009^{* *}$ & $\mathrm{O}_{3+4}^{6}$ & -0.0051 & -0.0221 & 1 & $\mathrm{O}_{\underline{3+4}}^{6}$ & -0.0113 & -0.0562 & 1 & $\mathrm{O}_{\underline{3+4}}^{6}$ & \multicolumn{2}{|c|}{$0.049 \quad 0.2759$} & 0.074 \\
\hline $\mathrm{O}_{3+4+1}$ & -0.0442 & -0.6205 & - & $\mathrm{O}_{3+4+1}$ & 0.0224 & 0.2734 & 0.28 & $\mathrm{O}_{3+4+1}$ & 0.0166 & 0.1944 & - & $\mathrm{O}_{3+4+1}$ & 0.0041 & 0.0667 & - \\
\hline $\mathrm{O}_{3+4+2}$ & 0.0128 & 0.4861 & - & $\mathrm{O}_{\underline{3+4}+2}$ & 0.0145 & 1 & - & $\mathrm{O}_{3+4+2}$ & - & - & - & $\mathrm{O}_{3+4+2}$ & - & - & - \\
\hline & $\mathrm{BF}$ & & & & H & & & & VE & & & & $B 2$ & & \\
\hline & $D$ & $D^{\prime}$ & $P$ & & $D$ & $D^{\prime}$ & $P$ & & $D$ & $D^{\prime}$ & $P$ & & $D$ & $D^{\prime}$ & $P$ \\
\hline$A_{s t}$ & -0.0523 & -0.3478 & 0.7381 & $\overline{A_{\text {st }}}$ & -0.0248 & -0.1538 & 1 & $A_{\text {st }}$ & 0.019 & 0.1296 & - & $\overline{A_{s t}}$ & -0.0136 & -0.0739 & 1 \\
\hline$A_{1}$ & 0.0081 & 0.0761 & 0.7381 & $A_{1}$ & 0 & 0 & 1 & $A_{1}$ & -0.0045 & -0.0505 & - & $A_{1}$ & 0.0086 & 0.0546 & 1 \\
\hline$A_{2}$ & 0.0442 & 1 & - & $A_{2}$ & 0.0248 & 1 & - & $A_{2}$ & -0.0145 & -0.254 & - & $A_{2}$ & 0.005 & 0.1897 & - \\
\hline $\mathrm{J}_{\mathrm{st}}$ & 0.0159 & 0.1289 & 0.5104 & $\mathrm{~J}_{\mathrm{st}}$ & -0.0041 & -0.0571 & 1 & $\mathrm{~J}_{\mathrm{st}}$ & -0.0258 & -0.2879 & 0.317 & $\mathrm{~J}_{\mathrm{st}}$ & 0.0167 & 0.116 & 0.461 \\
\hline$J_{1}$ & -0.0159 & -0.1289 & 0.5104 & $J_{1}$ & 0.0041 & 0.0571 & 1 & $\mathrm{~J}_{1}^{\mathrm{st}}$ & 0.0258 & 0.2879 & 0.317 & $J_{1}^{s t}$ & -0.0167 & -0.116 & 0.461 \\
\hline$U_{s t}$ & 0.0148 & 0.3345 & - & $U_{s t}$ & -0.0031 & -0.12 & - & $U_{s t}$ & -0.0057 & -0.3472 & - & $U_{s t}$ & 0.0075 & 0.1897 & - \\
\hline$U_{1}^{s t}$ & - & - & - & $U_{1}^{s t}$ & -0.0052 & -1 & - & $U_{1}^{s t}$ & - & - & - & $U_{1}^{s t}$ & 0.0066 & 1 & - \\
\hline$U_{1+2}$ & -0.0165 & -0.1011 & 0.8217 & $U_{1+2}$ & 0.031 & 0.2143 & 0.353 & $U_{1+2}$ & 0.0177 & 0.2167 & 0.58 & $U_{1+2}$ & -0.0045 & -0.0276 & 1 \\
\hline$U_{1+2+6}$ & 0.0017 & 0.0145 & 0.8217 & $U_{1+2+6}$ & -0.0227 & -0.2 & 0.332 & $U_{1+2+6}$ & -0.012 & -0.184 & 0.58 & $U_{1+2+6}$ & -0.0095 & -0.1296 & 0.79 \\
\hline $\mathrm{E}_{\mathrm{st}}$ & -0.0169 & -0.1257 & 0.4896 & $\mathrm{E}_{\mathrm{st}}$ & 0.0248 & 0.2667 & 0.249 & $\mathrm{E}_{\mathrm{st}}$ & -0.0511 & -0.5459 & - & $\mathrm{E}_{\mathrm{st}}$ & 0.0061 & 0.0423 & 0.808 \\
\hline$E_{8}$ & -0.0017 & -0.0134 & 1 & $E_{8}$ & -0.0124 & -0.0774 & 1 & $E_{8}$ & 0.0143 & 0.1086 & 0.603 & $\mathrm{E}_{8}$ & -0.0201 & -0.2747 & 0.42 \\
\hline$E_{1+2+9}$ & 0.0161 & 0.0761 & 0.5426 & $E_{1+2+9}$ & -0.032 & -0.1676 & 0.383 & $E_{1+2+9}$ & 0.0344 & 0.1876 & 0.197 & $E_{1+2+9}$ & 0.0181 & 0.1084 & 0.668 \\
\hline $\mathrm{E}_{1+2+9+12}$ & 0.0025 & 0.113 & - & $E_{1+2+9+12}$ & 0.0196 & 0.6333 & - & $E_{1+2+9+12}$ & 0.0025 & 0.1896 & - & $E_{1+2+9+12}$ & -0.0041 & -1 & - \\
\hline $\mathrm{O}_{\mathrm{st}}$ & -0.0359 & -0.1964 & 0.2102 & $\mathrm{O}_{\mathrm{st}}$ & -0.0165 & -0.1391 & 0.474 & $\mathrm{O}_{\mathrm{st}}$ & -0.0317 & -0.5983 & - & $\mathrm{O}_{\mathrm{st}}$ & 0.0167 & 0.116 & 0.617 \\
\hline $\mathrm{O}_{6}$ & - & - & - & $\mathrm{O}_{6}$ & - & - & - & $\mathrm{O}_{6}$ & - & - & - & $\mathrm{O}_{6}^{\mathrm{st}}$ & -0.0041 & -1 & - \\
\hline $\mathrm{O}_{3+4}$ & -0.005 & -0.0226 & 1 & $\mathrm{O}_{\underline{3+4}}$ & 0.0403 & 0.1814 & 0.191 & $\mathrm{O}_{3+4}$ & 0.0394 & 0.2358 & $\underline{0.049^{*}}$ & $\mathrm{O}_{3+4}$ & -0.045 & -0.2457 & 0.088 \\
\hline $\mathrm{O}_{\underline{3+4+1}}$ & 0.0233 & 0.2287 & 0.2345 & $\mathrm{O}_{3+4+1}$ & -0.0196 & -0.2235 & 0.418 & $\mathrm{O}_{\underline{3+4+1}}^{\frac{3+4}{4}}$ & -0.0233 & -0.2384 & 0.462 & $\mathrm{O}_{3+4+1}^{\frac{3+4}{3+1}}$ & 0.038 & 0.2633 & 0.132 \\
\hline $\mathrm{O}_{3+4+2}$ & 0.0177 & 1 & - & $\mathrm{O}_{3+4+2}$ & -0.0041 & -0.2667 & - & $\mathrm{O}_{3+4+2}$ & 0.0156 & 0.5948 & - & $\mathrm{O}_{3+4+2}$ & -0.0057 & -0.3472 & - \\
\hline
\end{tabular}

${ }^{\star} P<0.05,{ }^{* *} P<0.01$.

Table S3. Whole sample LD analysis.

\begin{tabular}{|c|c|c|c|}
\hline & $D$ & $D^{\prime}$ & Two tailed $P$ value \\
\hline$A_{S T}$ & -0.0036 & -0.0231 & 0.7840 \\
\hline$A_{1}$ & -0.0053 & -0.0550 & 0.7840 \\
\hline$A_{2}$ & 0.0088 & 0.1961 & - \\
\hline$J_{S T}^{2}$ & 0.0035 & 0.0227 & 0.7309 \\
\hline $\mathrm{J}^{1}$ & -0.0035 & -0.0227 & 0.7309 \\
\hline$U_{S T}$ & 0.0054 & 0.1068 & 0.3567 \\
\hline$U_{1}$ & -0.0013 & -0.4645 & - \\
\hline$U_{1+2}$ & -0.0105 & -0.067 & 0.1981 \\
\hline$U_{1+2+6}^{\frac{1+2}{2}}$ & 0.0064 & 0.0621 & 0.4316 \\
\hline$\frac{1+2+6}{E_{S T}}$ & -0.0107 & -0.0732 & 0.3114 \\
\hline $\mathrm{E}_{8}$ & -0.0016 & -0.0134 & 1.0000 \\
\hline$E_{1+2+9}^{8}$ & 0.0073 & 0.0341 & 0.3356 \\
\hline$E_{1+2+9+12}^{\frac{1+2+9}{1}}$ & 0.0049 & 0.2660 & - \\
\hline$\frac{\frac{1+2+9+12}{\mathrm{O}_{\mathrm{ST}}}}{\mathrm{n}}$ & -0.0200 & -0.1411 & $0.0278^{*}$ \\
\hline $\mathrm{O}_{6}$ & -0.0007 & -1.0000 & I \\
\hline $\mathrm{O}_{3+4}^{\circ}$ & 0.0129 & 0.0529 & 0.2114 \\
\hline $\mathrm{O}_{3+4+1}^{\frac{3+4}{4}}$ & 0.0016 & 0.0142 & 0.9235 \\
\hline $\mathrm{O}_{\underline{3+4+2}}^{\frac{3+4+1}{2}}$ & 0.0063 & 0.3748 & 0.0761 \\
\hline
\end{tabular}

${ }^{*} P<0.05$.
Table S4. Parameters of microsatellite variability.

\begin{tabular}{ccccc}
\hline Population & $A$ & $R$ & $H_{O}$ & $H_{E}$ \\
\hline B & 13.64 & 19.36 & 0.706 & 0.821 \\
H & 12.91 & 18.64 & 0.673 & 0.823 \\
PR & 14.18 & 17.73 & 0.732 & 0.835 \\
NB & 13.73 & 19.27 & 0.688 & 0.852 \\
BR & 15.91 & 25.91 & 0.732 & 0.846 \\
KH & 14.45 & 20.64 & 0.744 & 0.849 \\
VB & 14.45 & 20.64 & 0.721 & 0.853 \\
BZ & 14.36 & 20.36 & 0.694 & 0.847 \\
\hline
\end{tabular}

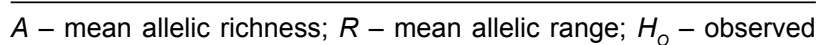
heterozygosity; $H_{E}$ - expected heterozygosity. 